\title{
Normal nasal patency: problems in obtaining standard reference values for the surgeon
}

\author{
M MOORE, R ECCLES \\ Common Cold Centre, Cardiff University, Wales, UK
}

\begin{abstract}
This review examines why there is no normal range of nasal patency available to the surgeon when assessing nasal obstruction, and discusses the factors that influence nasal patency. Current normal ranges are examined and criticised because of the variability of normal values and the poor sampling methods used. Instability of physiological nasal patency is related to factors such as the nasal cycle and the nose's direct exposure to the external environment. Decongestion of the nose is proposed as a way of stabilising anatomical nasal patency, and measurements of patency in this state may be more useful to the surgeon. Population studies are needed to establish a normal range, but these studies must control for factors such as age, height, sex, and nasal shape and size related to climatic adaptation. Rather than classify populations according to unscientific categories such as race, anthropometric measures such as the nasal index are proposed.
\end{abstract}

Key words: Nasal Obstruction; Nasal Index; Nasal Patency; Rhinology; Race; Nasal Cycle

\section{Introduction}

Advances in medicine are dependent on the determination of normal function. Normal ranges of parameters such as lung function, body temperature and blood sugar are essential in determining the presence of disease and deciding whether intervention is required to restore normal values.

Nasal obstruction is one of the most common complaints presenting to ENT surgeons, but treatment is usually initiated without any reference to a normal range of nasal patency. This approach would never be undertaken for any patient presenting with obstructive pulmonary disease, as reference to normal lung function tests such as forced expiratory volume (FEV) and peak expiratory flow rate (PEFR) would be considered mandatory for diagnosis and, in many cases, for monitoring the efficacy of any treatment.

Nasal patency can be measured by rhinomanometry, acoustic rhinometry and the simpler measure of peak nasal inspiratory flow. Several published studies have attempted to define a normal range of nasal patency. However, a recent review on the use of objective measures to select patients for nasal surgery stated that 'the fact that validated normal values are still lacking is a major problem', ${ }^{1}$ and this highlights the current problem in rhinology as regards a 'normal' range of nasal patency.
This paper will discuss why normal nasal patency is so difficult to define, and why population studies of nasal patency pose special problems.

\section{Physiological nasal patency is unstable}

The nose and the external environment

The introduction to this review highlighted the discrepancy between pneumologist and rhinologists. Pneumologist have access to useful normal ranges for lung function, whereas rhinologists have not yet succeeded in establishing normal ranges for nasal patency.

However, this comparison is not justified, as the nose and lungs have one major difference that may make the definition of normal nasal patency difficult if not impossible. The nose is directly exposed to the external environment, and is subject to major changes in temperature and humidity, as well as to direct exposure to pollutants and particulate matter. The nose acts as the 'air conditioner' that protects the lungs from the external environment. The lungs operate as part of the internal environment of the body, at a constant temperature of $37^{\circ} \mathrm{C}$, and with air that is clean and fully saturated with water; in contrast, the nasal airway is directly exposed to unconditioned inspired air. Whereas lung function studies test the lungs under the same controlled internal environment, nasal patency tests are influenced by the external environment, and one 
would not expect nasal patency to be as stable as lung function. The lower lung airways are sterile and rarely infected, whereas the nose is directly exposed to inhaled bacteria, viruses and fungi: as a result, upper airway infections are a common occurrence, with children suffering seven to 10 symptomatic viral infections each year, and adults between two and five symptomatic infections. $^{2}$

\section{The nasal cycle}

The nasal airways exhibit spontaneous changes in congestion and decongestion of the large veins in the nasal mucosa, which cause fluctuations in nasal airflow between the nasal passages. This is often described as the nasal cycle. ${ }^{3}$ The nasal patency and the airflow through the two nasal passages are usually asymmetrical, with the dominance of nasal airflow alternating over a period of several hours.

The first objective measures of nasal patency were made by Stoksted ${ }^{4}$ in 1952, using a form of rhinomanometry, and demonstrated the instability of both unilateral and total nasal patency in healthy adult subjects. ${ }^{5}$ Some subjects exhibit reciprocal changes in unilateral nasal patency, so that total nasal patency remains relatively constant, but others exhibit irregular changes in unilateral patency which cause irregular changes in total nasal patency. Flanagan and Eccles' research (P Flanagan, unpublished data; Flanagan and Eccles ${ }^{6}$ ) on 52 healthy subjects confirmed Stoksted's earlier findings. ${ }^{5}$ Figure 1 illustrates two examples of 'normal' nasal airflow. Figure 1(a) illustrates spontaneous and reciprocal changes in unilateral nasal patency, while Figure 1(b) illustrates changes in unilateral patency which are more in phase with each other. In Figure 1, total nasal patency varies by 23 per cent in part (a) and by 42 per cent in part (b), while spontaneous changes in unilateral patency are much greater.

Flanagan's 1996 study (P Flanagan, unpublished data) calculated the mean unilateral nasal airflow as $183 \mathrm{~cm}^{3} /$ second ( \pm standard deviation $90 \mathrm{~cm}^{3} /$ second), based on 830 measurements recorded in 52 healthy subjects over eight hours of recording in each subject. The large standard deviation reflects the large range of unilateral airflows recorded, from 39 to $536 \mathrm{~cm}^{3}$ / second (airflow was measured by posterior rhinomanometry at a sample pressure of $75 \mathrm{~Pa}$ ). Similar results for normal unilateral patency have been reported by Cole, ${ }^{7}$ who observed that, in healthy subjects, one nasal passage often became almost completely obstructed due to the normal physiological congestion phase of the nasal cycle.

The great physiological variation in both unilateral and total nasal patency means that any single measurement of either parameter provides little information about the 'normal' nasal patency in any one subject. This demonstrates the difficulty in defining a normal range of physiological nasal patency for use by the rhinologist.
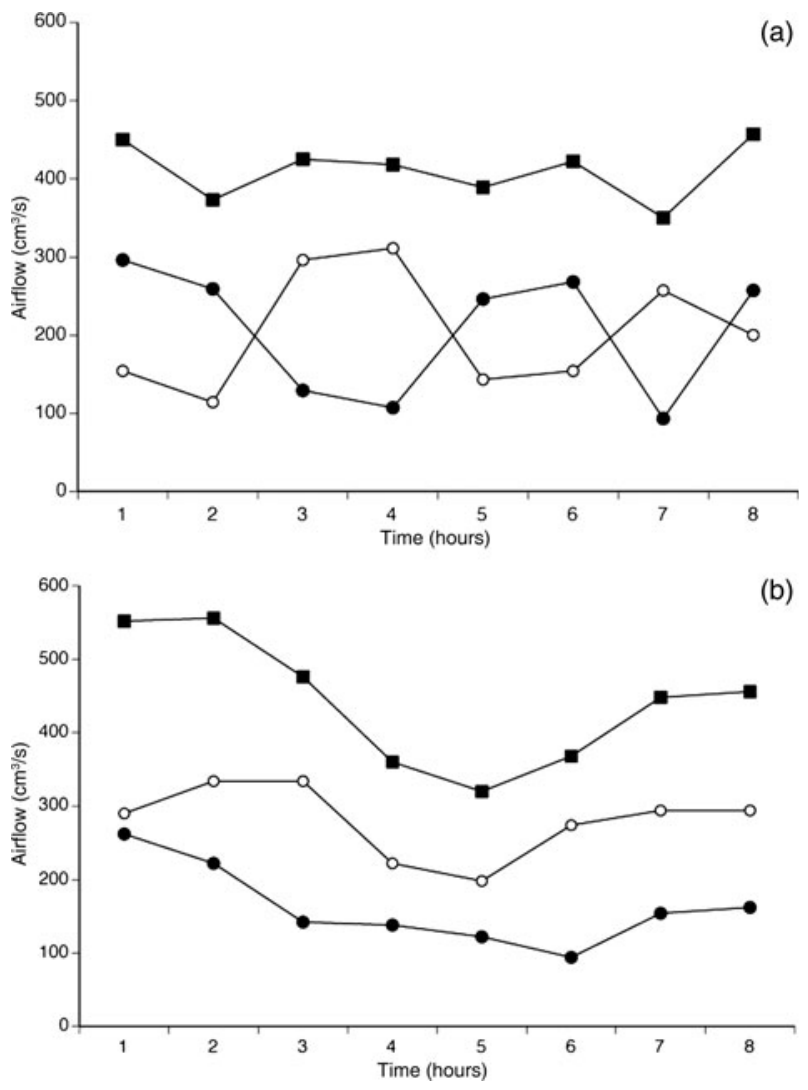

FIG. 1

Rhinomanometric data showing different types of changes in unilateral and total nasal airflow: (a) spontaneous, reciprocal changes in unilateral nasal patency; (b) spontaneous unilateral nasal patency changes which are more in phase with each other. Airflow measured at a sample pressure of $75 \mathrm{~Pa}$. Adapted with permission (P Flanagan, unpublished data). $\bigcirc=$ right nasal airflow; $\bullet=$ left nasal airflow; = total airflow

\section{Anatomical nasal patency is stable}

Physiological nasal patency is unstable, as discussed above. However, decongestion of the nasal blood vessels by application of a topical nasal decongestant, or as a result of exercise, eliminates any effects of the nasal blood vessels on nasal patency. Decongestion allows the measurement of nasal patency determined solely by the hard tissues of the nose. This is often termed the 'anatomical' or 'skeletal' nasal patency. Application of topical decongestants abolishes the spontaneous fluctuations in nasal patency associated with the nasal cycle, for up to six hours. ${ }^{9}$ Exercise has a similar but shorter duration of decongestant effect on both sides of the nose. ${ }^{10}$ Broms stated that '[n]o upper normal limit can be given for resistance in a nasal cavity that has not been decongested'. Holmström stated that:

The wide variability of the nasal mucosa, which is influenced by several external and internal factors, makes it unlikely that we will ever have "normal values' for nasal patency before decongestion. After decongestion, however, the situation is different... the decongested nasal passage can be 
evaluated based on the influence of the skeleton (nasal cartilage and bone structures). ${ }^{1}$

Any normal range of nasal patency can only be determined after nasal decongestion. However, in order to define such a normal range of nasal patency, several other factors that can influence nasal patency must be considered. Tables that predict lung function parameters such as FEV and PEFR take into consideration factors such as height, sex and age, and similar factors must be considered when trying to predict a normal range of nasal patency.

\section{Factors that influence anatomical nasal patency}

The nose is the entrance to the respiratory tract. Many of the factors that influence lung size and function also influence nasal size and patency.

\section{$\operatorname{Sex}$}

Within medicine, measurements that are associated with patient size are often interpreted with respect to the patient's sex, since adult males are typically of larger build than adult females. Nasal patency has been shown to differ according to sex, with men in general having a greater nasal patency than women. ${ }^{11-16}$

\section{Age}

The size of the airway will increase with normal growth from infancy to adulthood. ${ }^{17-20}$ This increase in respiratory tract size will affect nasal size and increase nasal patency. ${ }^{11,21}$ Children suffer from a greater number of upper respiratory tract infections than adults, contributing to an increase in nasal mucosa congestion and mucus production, as well as to changes in the lymphoid adenoid tissue, which might also contribute to nasal resistance. ${ }^{21}$

The structure of the vestibule and nasal valve region is formed by cartilage. Cartilage is highly elastic in infants but becomes more rigid with age. Changes in the elasticity of nasal structures may influence nasal patency. Nasal patency has been shown to differ with age, with a general decrease in patency with increasing age in adults; ${ }^{12}$ however, this is probably due to agerelated changes in the nasal mucosa. ${ }^{12,18}$

\section{Height}

As already mentioned, Broms ${ }^{8}$ found an association between nasal patency and height. As with sex, the taller a person is, the larger their airway and nose are likely to be. A taller person will also have a larger body generally, and therefore larger organs with a greater oxygen requirement. Their lungs will be proportionally bigger, with a larger chest wall to draw air into the upper respiratory tract, as noted from pulmonary function tests. Nasal patency has been shown to increase with height. ${ }^{12,21,22}$

\section{Weight}

Weight, like height, is proportional to the size of the individual's body: a tall person is likely to weigh more.

Obesity is reported to be a causative factor in snoring, ${ }^{23}$ acting by narrowing the airway particularly in the region of the pharynx. This may result in increased effort of breathing in an attempt to draw more air in through the nose. However, obesity does not play as great a role within the nasal cavity since there is little adipose tissue there, in contrast to the pharynx.

Weight appears to be associated with nasal flow in both children ${ }^{21}$ and adults. ${ }^{24}$

\section{Race}

The appearance of the nose is often considered characteristic of an individual's racial origin. European noses are described as leptorrhine, African noses as platyrrhine and Asian-Oriental noses as between the two. ${ }^{25}$ Differences in the shape and size of the nose have been proposed to be an adaptation to climate, with the large, open platyrrhine nose having evolved in a warm, humid environment where there was little need for air conditioning, and the narrow leptorrhine nose having evolved in colder climates where inspired air needed more warming. ${ }^{26,27}$

Various authors have investigated the differences in nasal patency between different racial groups. ${ }^{28-31}$ However, classification of patients according to racial characteristics has been reported to be unscientific as there is no clear definition of race; rather, it has been proposed that nasal shape and size are better described in terms of nasal height and width, expressed as a nasal index. ${ }^{27,32,33}$

\section{Problems with current nasal patency data}

Published studies have quoted normal values of nasal patency. Most frequently, anterior rhinomanometry has been the objective measurement used, but ranges for methods such as acoustic rhinometry and peak nasal inspiratory flow have also been published. Unfortunately, these studies have varied quite considerably in their design, as well as in the values they have obtained. Tables I and II show published mean values for normal unilateral and total nasal resistance of the decongested nose, and these parameters are also illustrated in Figures 2 and 3. Normal mean values, derived using anterior rhinomanometry in the decongested adult nose, vary from 0.17 to $0.43 \mathrm{~Pa} / \mathrm{cm}^{3}$ / second for unilateral nasal patency ${ }^{1,7,22,34-42}$ and from 0.06 to $0.25 \mathrm{~Pa} / \mathrm{cm}^{3} /$ second for total nasal patency. ${ }^{7,13,22,28,31,34,36,37,40-45}$ As can be noticed from Tables I and II, not all these studies provide a range: some provide an upper limit while others supply a mean.

In contrast, corresponding results in the nondecongested adult nose vary substantially, with reported mean values of 0.06 to $0.81 \mathrm{~Pa} / \mathrm{cm}^{3} /$ second 


\begin{tabular}{|c|c|c|c|c|}
\hline \multicolumn{5}{|c|}{$\begin{array}{c}\text { TABLE I } \\
\text { ADULT UNILATERAL NASAL RESISTANCE* POST- } \\
\text { DECONGESTION: PUBLISHED NORMAL VALUES }\end{array}$} \\
\hline \multirow[t]{2}{*}{ Study } & \multirow[t]{2}{*}{$\operatorname{Sbj}(n)$} & \multicolumn{2}{|c|}{$\begin{array}{c}\text { Range } \\
\left(\mathrm{Pa} / \mathrm{cm}^{3} / \mathrm{s}\right)\end{array}$} & \multirow[t]{2}{*}{$\begin{array}{c}\text { Mean } \\
\left(\mathrm{Pa} / \mathrm{cm}^{3} / \mathrm{s}\right)\end{array}$} \\
\hline & & Min & Max & \\
\hline Jalowayski et al. ${ }^{34}$ & 20 & - & - & 0.43 \\
\hline Jessen \& Malm ${ }^{22}$ & 100 & - & - & 0.36 \\
\hline Szücs et al. ${ }^{39}$ & 100 & - & - & 0.3 \\
\hline Kenyon $^{38}$ & 25 & - & - & 0.28 \\
\hline Szücs \& Clement ${ }^{35}$ & 15 & 0.25 & 0.3 & 0.26 \\
\hline Cole $^{7}$ & 891 & - & 0.4 & 0.23 \\
\hline Pallanch et $a l_{.}^{41}$ & 80 & 0.09 & 0.52 & 0.22 \\
\hline Gordon et al. ${ }^{37}$ & 14 & 0.14 & 0.35 & 0.17 \\
\hline Sipilä et al. ${ }^{36}$ & 97 & - & 0.3 & - \\
\hline Sipilä ${ }^{\dagger}$ & - & 0.15 & 0.5 & - \\
\hline McCaffrey \& Kern ${ }^{40}$ & 23 & - & 0.69 & - \\
\hline Holmström ${ }^{1}$ & - & - & 1.0 & - \\
\hline
\end{tabular}

*Also termed nasal patency. ${ }^{\dagger} \mathrm{J}$ Sipilä, personal communication to Holmström; ${ }^{1}$ data confirmed as unilateral values (M Holmström, person communication). $\mathrm{Sbj}=$ subjects; $\min =$ minimum; $\max =$ maximum; $-=$ not advised

(range: $0.01-2.4 \mathrm{~Pa} / \mathrm{cm}^{3} /$ second) for unilateral nasal patency and 0.03 to $0.32 \mathrm{~Pa} / \mathrm{cm}^{3} /$ second (range: $0.01-0.9 \mathrm{~Pa} / \mathrm{cm}^{3} /$ second) for total nasal patency. The studies shown in Tables I and II used different methods to measure resistance, and expressed resistance in several different units. In order to allow comparison between these studies, units of resistance have been converted so that all values are expressed in $\mathrm{Pa} / \mathrm{cm}^{3} /$ second. Such conversion is simple for some units but more problematic for others; the reader is referred to the original papers to obtain the raw data for each study.

Within the literature, some studies ${ }^{24}$ have included as few as 10 normal participants, whereas others ${ }^{7}$ have had as many as 891. The ages of participants has varied between studies, with some assessing

\section{TABLE II}

ADULT TOTAL NASAL RESISTANCE* POSTDECONGESTION: PUBLISHED NORMAL VALUES

\begin{tabular}{|c|c|c|c|c|}
\hline \multirow[t]{2}{*}{ Study } & \multirow[t]{2}{*}{$\operatorname{Sbj}(n)$} & \multicolumn{2}{|c|}{$\begin{array}{c}\text { Range } \\
\left(\mathrm{Pa} / \mathrm{cm}^{3} / \mathrm{s}\right)\end{array}$} & \multirow[t]{2}{*}{$\begin{array}{c}\text { Mean } \\
\left(\mathrm{Pa} / \mathrm{cm}^{3} / \mathrm{s}\right)\end{array}$} \\
\hline & & Min & Max & \\
\hline Eiser $^{45}$ & - & - & - & 0.25 \\
\hline Jalowayski et al. ${ }^{34}$ & 20 & - & - & 0.21 \\
\hline Jessen \& Malm 22 & 100 & - & - & 0.18 \\
\hline Calhoun et al. ${ }^{28}$ & 130 & 0.09 & 0.85 & 0.18 \\
\hline Shelton et al. ${ }^{42}$ & 10 & 0.14 & 0.22 & 0.18 \\
\hline Canbay \& Bhatia ${ }^{31}$ & 74 & 0.1195 & 0.236 & 0.1575 \\
\hline McCaffrey \& Kern ${ }^{40}$ & 23 & - & 0.29 & 0.15 \\
\hline Gleeson et al. ${ }^{44}$ & 12 & - & - & 0.15 \\
\hline Postema et $_{\text {al. }}{ }^{13 \dagger}$ & 68 & - & 0.23 & 0.14 \\
\hline Cole $^{7}$ & 891 & - & 0.15 & 0.09 \\
\hline Pallanch et al. ${ }^{41}$ & 80 & 0.04 & 0.15 & 0.08 \\
\hline Gordon et al. ${ }^{37}$ & 14 & 0.03 & 0.1 & 0.06 \\
\hline Sipilä et al. ${ }^{36}$ & 97 & - & 0.15 & - \\
\hline Gammert et al. $^{43}$ & 56 & - & 0.3 & - \\
\hline
\end{tabular}

*Also termed nasal patency. ${ }^{\dagger}$ Males only. Sbj = subjects; $\min =$ minimum; $\max =$ maximum; $-=$ not advised paediatric populations (Papachristou et al. ${ }^{11}$ Prescott and Prescott, ${ }^{21}$ Risavi et al. ${ }^{46}$ and Zapletal and Chalupová ${ }^{47}$ ) and others adult populations. In the adult studies, nasal patency is generally not related to subject age specifically; rather, an age range is quoted. Some studies have decongested the nasal mucosa prior to measurement, many have not, and some have not specified whether decongestion was used. There is variability in the methods of objective measurement used, and in whether unilateral or total patency has been studied. Some studies have not reported what ethnic population group their participants have been taken from, and include all patients in one 'normal' group. Some studies have progressed further by comparing the relationship of nasal patency with other factors such as sex, age, height, race, weight and smoking habits. Some studies have identified that their subjects were taken from a homogeneous group and as such cannot be considered 'normal' for all population groups.

One of the largest studies was performed by Cole, ${ }^{7}$ who studied 2500 adult patients referred to an ENT clinic, and identified 891 who were 'unobstructed'. However, it is difficult to accept that this study provides a normal range of nasal patency, as the 'normal' population had all been referred to an ENT clinic, presumably for symptomatic problems within the upper airway. McCaffrey and $\operatorname{Kern}^{40}$ reported 'normal' values for 23 patients, who were identified from 1000 referred to an ENT clinic for 'rhinologic complaints', but who were found to be asymptomatic on normal rhinoscopy.

Hospital-based studies can be criticised for using patients referred to ENT clinics in order to obtain a normal range of nasal patency, and none of these studies has controlled for all the factors that influence nasal patency, as discussed above. Holmström ${ }^{1}$ reported that we are still awaiting 'a large series of measures, preferably population-based and stratified according to age, sex, height and weight'. However, this type of population study is not easy to conduct.

\section{Is a population-based study achievable?}

Any normal range of nasal patency must first be defined in terms of the population, before results can be stratified for factors such as age and sex. However, defining the study population for such research is a major problem. As discussed above, the nose, unlike internal organs such as the lungs, is directly exposed to the external environment, and there are major differences in nasal shape and size according to climate. The narrow leptorrhine nose is reported to have a lower patency than the broader platyrrhine nose, ${ }^{25,29-31}$ and there are climatic and racial differences in nasal shape and size when one compares indigenous peoples worldwide, from Siberia to Africa. ${ }^{26,48,49}$ Classifying subjects according to geographical location or race is fraught with difficulty, especially as regards the nose. $^{33,50,51}$ Any study in a large, modern city will 


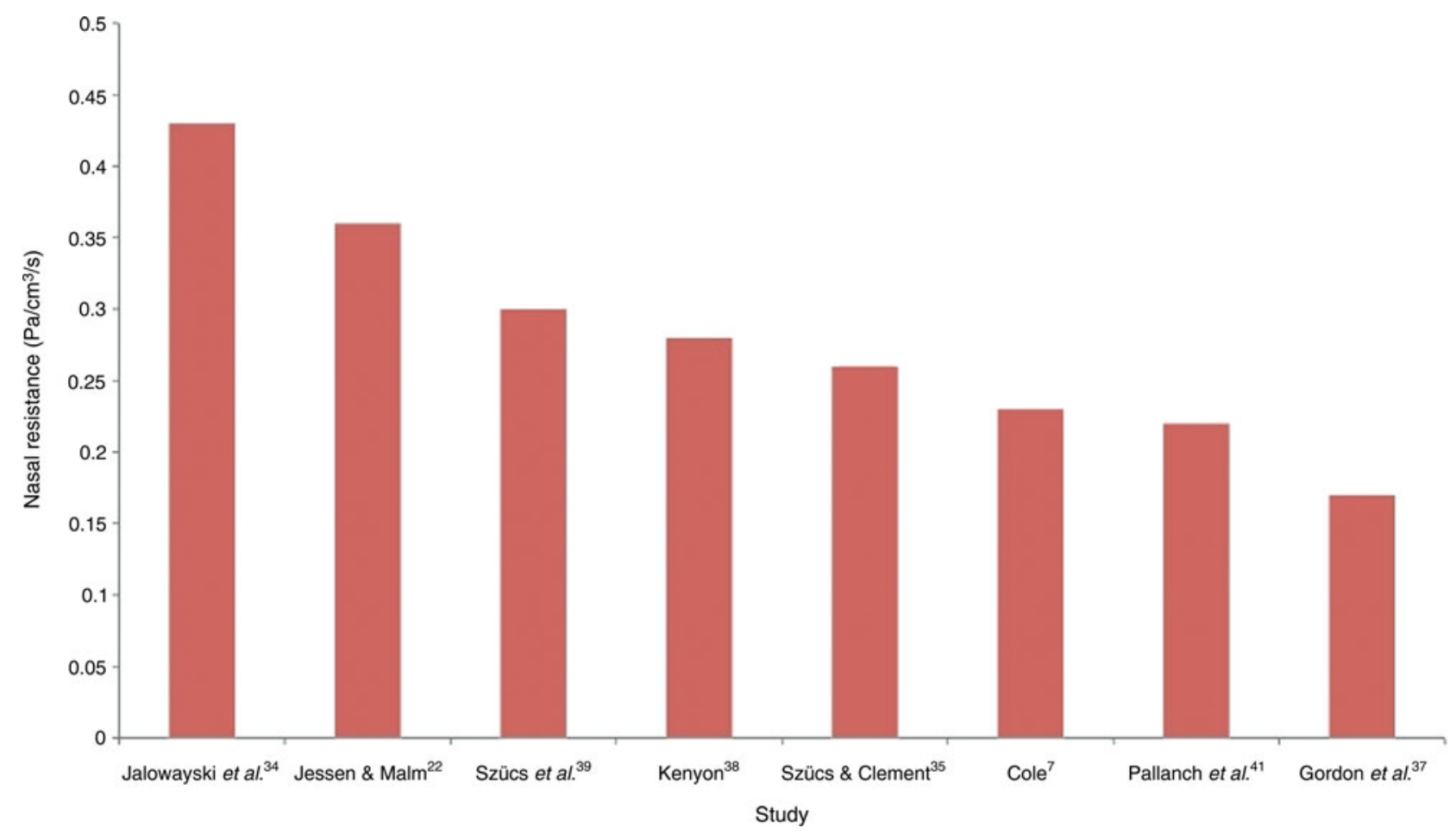

FIG. 2

Published normal values for mean unilateral nasal resistance after decongestion in adults. Original data have been converted to common units of resistance, expressed as $\mathrm{Pa} / \mathrm{cm}^{3} / \mathrm{s}$, to enable comparison between studies.

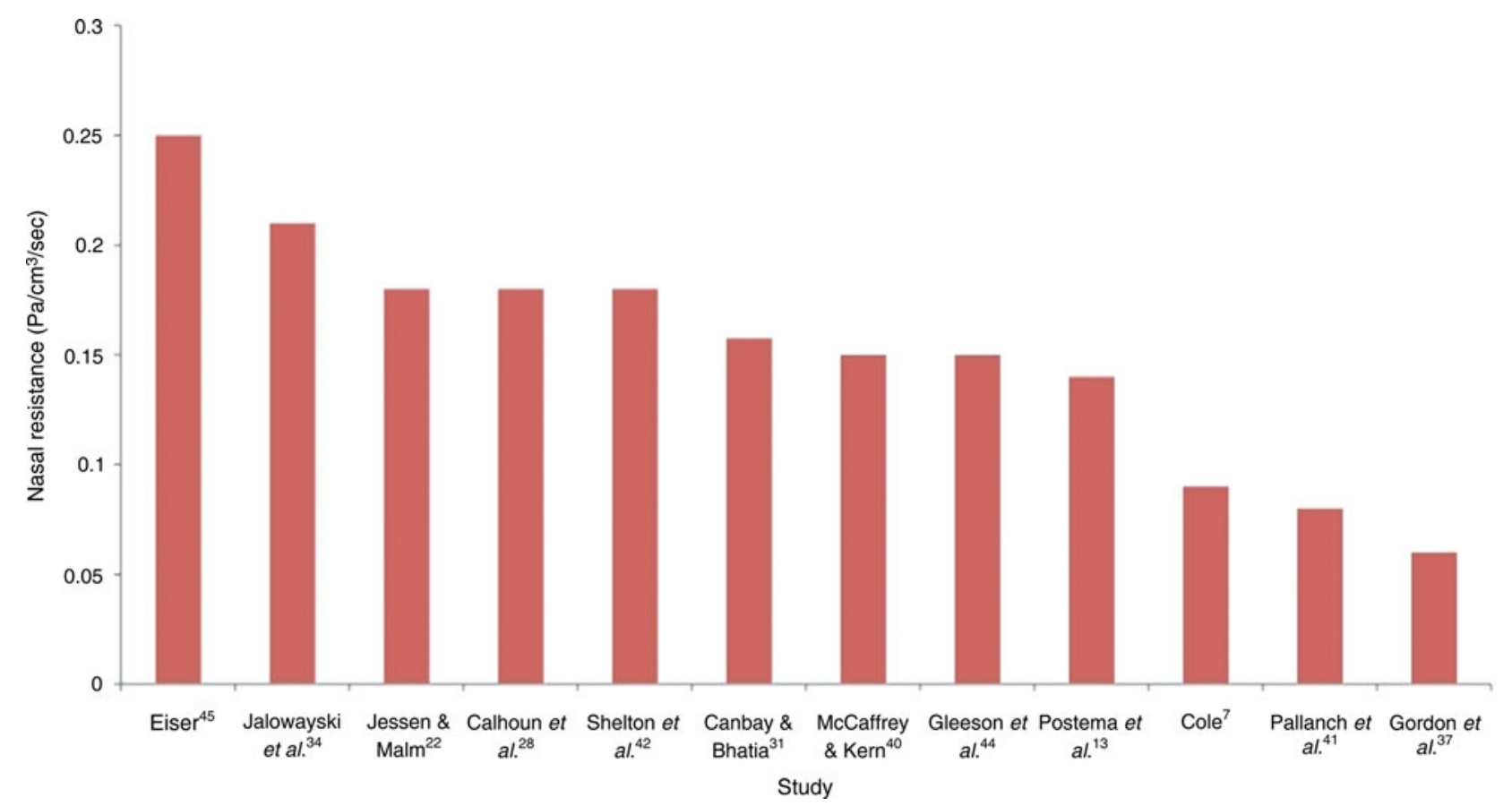

FIG. 3

Published normal values for mean total nasal resistance after decongestion in adults. Original data have been converted to common units of resistance, expressed as $\mathrm{Pa} / \mathrm{cm}^{3} / \mathrm{s}$, to enable comparison between studies.

recruit a mixed population according to the immigration history of that city. Cities such as London, New York and Vancouver have a complex mix of immigrant groups, with mixed marriages across groups making the population even more complex and diverse. It is not possible to classify individuals according to race, as terms such as Caucasian, Asian and Mediterranean cannot be defined in any scientific way. ${ }^{51}$ 
Population studies have been used to provide reference values for lung function tests, as the variation in lung function with so-called racial characteristics is less than that observed for the nose, for reasons discussed above. However, reference values for lung function have also been criticised as not fit for purpose when applied to populations of mixed origin, as in the USA, where the population consists of groups of European ('Caucasian'), African and MexicanAmerican groups. ${ }^{52}$

Despite its widespread use in clinical literature, the term Caucasian has no scientific definition, and use of this term has been criticised when applied to both nasal and lung function tests. ${ }^{33,50,53}$ Population studies may be possible in less mobile communities, where there is a static population of indigenous residents, such as in some Iranian cities. ${ }^{54}$ However, for most of the developed world the mixing of populations make homogeneous population studies unfeasible.

The population study by Broms ${ }^{8}$ is often used as a source of reference values for the decongested nose, as the study did stratify for height. However, this population was also very limited, as two-thirds of the subjects comprised men undergoing training as pilots in the Swedish Air Force.

Rather than attempting to categorise a study population using unscientific racial terms that have no clear definition, it may be more useful to describe the population in terms of anthropometric measurements such as nasal height and alar width, and then to calculate the nasal index. By measuring the width of the base of the nose and the height of the nose, the nasal index can be calculated by the following formula: ${ }^{33}$

\section{Width of nose $\times 100 /$ height of nose $=$ nasal index}

When conducting large population studies, the rhinologist may find the above formula to be a more relevant discriminator than race, and a better basis for reference tables of normal nasal patency. ${ }^{32}$

\section{Conclusion}

Unlike the pneumologist, the rhinologist currently has no standard reference values for nasal function which are stratified according to factors such as age and height. Because of the great variation in unilateral and total patency associated with the nasal cycle, normal physiological nasal patency is difficult to define. Decongesting the nose gives a more stable anatomical nasal patency, and measurements of patency in this state may be more useful to the surgeon. The nose is directly exposed to the external environment, and the shape and size of the nose have been shown to vary with the climate, from leptorrhine to platyrrhine noses. There is some evidence that nasal patency may also vary with these climatic variations. Population studies on nasal patency are difficult because racial classifications of populations are unscientific. Populations may be better defined by nasal anthropometric measures such as the nasal index, rather than by reference to race or geographical location.

\section{References}

1 Holmström M. The use of objective measures in selecting patients for septal surgery. Rhinology 2010;48:387-93

2 Johnston S, Holgate S. Epidemiology of viral respiratory infections. In: Myint S, Taylor-Robinson D, eds. Viral and Other Infections of the Human Respiratory Tract. London: Chapman \& Hall, 1996;1-38

3 Heetderks DL. Observations on the reaction of normal nasal mucous membrane. Am J Med Sci 1927;174:231-44

4 Stoksted P. Rhinometric measurements for determination of the nasal cycle. Acta Otolaryngol Suppl 1953;109:159-75

5 Stoksted P. The physiologic cycle of the nose under normal and pathologic conditions. Acta Otolaryngol 1952;42:175-9

6 Flanagan P, Eccles R. Spontaneous changes of unilateral nasal airflow in man. A re-examination of the 'nasal cycle'. Acta Otolaryngol 1997;117:590-5

7 Cole P. Nasal airflow resistance: a survey of 2500 assessments. Am J Rhinol 1997;11:415-20

8 Broms P. Rhinomanometry. III. Procedures and criteria for distinction between skeletal stenosis and mucosal swelling. Acta Otolaryngol 1982;94:361-70

9 Soubeyrand L. Action of vasomotor drugs on the nasal cycle and ciliary function (rhinometric and biological study) [in French]. Rev Laryngol Otol Rhinol (Bord) 1964;85:49-113

10 Dallimore NS, Eccles R. Changes in human nasal resistance associated with exercise, hyperventilation and rebreathing. Acta Otolaryngol 1977;84:416-21

11 Papachristou A, Bourli E, Aivazi D, Futzila E, Papastavrou T, Konstandinidis $\mathrm{T}$ et al. Normal peak nasal inspiratory flow rate values in Greek children and adolescents. Hippokratia 2008; 12:94-7

12 Ottaviano G, Scadding GK, Coles S, Lund VJ. Peak nasal inspiratory flow; normal range in adult population. Rhinology 2006;44:32-5

13 Postema CA, Huygen PL, Lecluse RG, Wentges RT. The lateralization percentage as a measure of nasal flow asymmetry in active anterior rhinomanometry. Clin Otolaryngol Allied Sci 1980;5:165-70

14 Millqvist E, Bende M. Reference values for acoustic rhinometry in subjects without nasal symptoms. Am J Rhinol 1998;12: $341-3$

15 Shelton DM, Eiser NM. Evaluation of active anterior and posterior rhinomanometry in normal subjects. Clin Otolaryngol Allied Sci 1992;17:178-82

16 Suzina AH, Hamzah M, Samsudin AR. Objective assessment of nasal resistance in patients with nasal disease. J Laryngol Otol 2003;117:609-13

17 Abramson Z, Susarla S, Troulis M, Kaban L. Age-related changes of the upper airway assessed by 3-dimensional computed tomography. J Craniofac Surg 2009;20(suppl 1):657-63

18 Lindemann J, Sannwald D, Wiesmiller K. Age-related changes in intranasal air conditioning in the elderly. Laryngoscope 2008; 118: $1472-5$

19 Lindemann J, Tsakiropoulou E, Konstantinidis I, Lindemann K. Normal aging does not deteriorate nose-related quality of life: assessment with "NOSE" and "SNOT-20" questionnaires. Auris Nasus Larynx 2010;37:303-7

20 Sforza C, Grandi G, De Menezes M, Tartaglia GM, Ferrario VF. Age- and sex-related changes in the normal human external nose. Forensic Sci Int 2011;204:205

21 Prescott CA, Prescott KE. Peak nasal inspiratory flow measurement: an investigation in children. Int $J$ Pediatr Otorhinolaryngol 1995;32:137-41

22 Jessen M, Malm L. Use of pharmacologic decongestion in the generation of rhinomanometric norms for the nasal airway. $\mathrm{Am}$ J Otolaryngol 1988;9:336-40

23 Bloom JW, Kaltenborn WT, Quan SF. Risk factors in a general population for snoring. Importance of cigarette smoking and obesity. Chest 1988;93:678-83

24 Crouse U, Laine-Alava MT. Effects of age, body mass index, and gender on nasal airflow rate and pressures. Laryngoscope 1999; 109:1503-8 
25 Ohki M, Naito K, Cole P. Dimensions and resistances of the human nose: racial differences. Laryngoscope 1991;101: 276-8

26 Thomson A, Dudley Buxton LH. Man's nasal index in relation to certain climatic conditions. The Journal of the Royal Anthropological Institute of Great Britain and Ireland 1923; 53:92-122

27 Wolpoff MH. Climatic influence on the skeletal nasal aperture. Am J Phys Anthropol 1968;29:405-23

28 Calhoun KH, House W, Hokanson JA, Quinn FB. Normal nasal airway resistance in noses of different sizes and shapes. Otolaryngol Head Neck Surg 1990;103:605-9

29 Corey JP, Gungor A, Nelson R, Liu X, Fredberg J. Normative standards for nasal cross-sectional areas by race as measured by acoustic rhinometry. Otolaryngol Head Neck Surg 1998; 119:389-93

30 Jones AG, Bhatia S. A study of nasal respiratory resistance and craniofacial dimensions in white and West Indian black children. Am J Orthod Dentofacial Orthop 1994;106:34-9

31 Canbay EI, Bhatia SN. A comparison of nasal resistance in white Caucasians and blacks. Am J Rhinol 1997;11:73-5

32 Leong SC, Eccles R. A systematic review of the nasal index and the significance of the shape and size of the nose in rhinology. Clin Otolaryngol 2009;34:191-8

33 Leong SC, Eccles R. The use of race as a demographic variable in clinical research. Rhinology 2010;48:3-6

34 Jalowayski AA, Yuh YS, Koziol JA, Davidson TM. Surgery for nasal obstruction - evaluation by rhinomanometry. Laryngoscope 1983;93:341-5

35 Szücs E, Clement PA. Acoustic rhinometry and rhinomanometry in the evaluation of nasal patency of patients with nasal septal deviation. Am J Rhinol 1998;12:345-52

36 Sipilä JI, Suonpää JT, Kortekangas AE, Laippala PT. Rhinomanometry before septoplasty - an approach to clinical material with diverse nasal symptoms. Am J Rhinol 1992;6: $17-22$

37 Gordon AS, McCaffrey TV, Kern EB, Pallanch JF. Rhinomanometry for preoperative and postoperative assessment of nasal obstruction. Otolaryngol Head Neck Surg 1989;101: 20-6

38 Kenyon GS. Phase variation in nasal airways resistance assessed by active anterior rhinomanometry. J Laryngol Otol 1987;101: 910-16

39 Szücs E, Kaufman L, Clement PA. Nasal resistance - a reliable assessment of nasal patency? Clin Otolaryngol Allied Sci 1995; 20:390-5

40 McCaffrey TV, Kern EB. Clinical evaluation of nasal obstruction. A study of 1,000 patients. Arch Otolaryngol 1979;105: $542-5$

41 Pallanch JF, McCaffrey TV, Kern EB. Normal nasal resistance. Otolaryngol Head Neck Surg 1985;93:778-5
42 Shelton DM, Pertuze J, Gleeson MJ, Thompson J, Denman WT, Goff J et al. Comparison of oscillation with three other methods for measuring nasal airways resistance. Respir Med 1990;84: $101-6$

43 Gammert C, Hampl K, Herrmann P. Normal values in rhinomanometry [in German]. HNO 1988;36:399-405

44 Gleeson MJ, Youlten LJ, Shelton DM, Siodlak MZ, Eiser NM, Wengraf CL. Assessment of nasal airway patency: a comparison of four methods. Clin Otolaryngol Allied Sci 1986;11:99-107

45 Eiser N. The hitch-hikers guide to nasal airway patency. Respir Med 1990;84:179-83

46 Risavi R, Pisl Z, Sprem N, Klapan I. Rhinomanometrical findings after septoplasty in children. Int J Pediatr Otorhinolaryngol 1988; 16:149-55

47 Zapletal A, Chalupová J. Nasal airflow and resistance measured by active anterior rhinomanometry in healthy children and adolescents. Pediatr Pulmonol 2002;33:174-80

48 Davies A. Man's nasal index in relation to climate. Man 1929; 29:8-14

49 Franciscus RG, Long JC. Variation in human nasal height and breadth. Am J Phys Anthropol 1991;85:419-27

50 Bhopal R, Donaldson L. White, European, Western, Caucasian, or what? Inappropriate labeling in research on race, ethnicity, and health. Am J Public Health 1998;88:1303-7

51 Leong SC, Eccles R. Race and ethnicity in nasal plastic surgery: a need for science. Facial Plast Surg 2010;26:63-8

52 Crapo RO. The role of reference values in interpreting lung function tests. Eur Respir J 2004;24:341-2

53 Kiviranta K, Haahtela T. Caucasian race and lung function: time to revisit the racial groups used in reference values. Eur Respir $J$ 2006;28: 1280

54 Golshan M, Amra B, Soltani F, Crapo RO. Reference values for lung volumes in an Iranian population: introducing a new equation model. Arch Iran Med 2009;12:256-61

Address for correspondence:

Mr Matthew Moore,

ENT Research Fellow,

Common Cold Centre,

Cardiff University,

Cardiff CF10 3AX, Wales, UK

Fax: +44 (0)2920874093

E-mail: matthew.moore@doctors.org.uk

Mr M Moore takes responsibility for the integrity of the content of the paper

Competing interests: None declared 